\title{
Waste in Hiring and Discharging Employees*
}

\author{
A Discussion of an Important Industrial Problem
}

\author{
By Magnus W. Alexander
}

Г Iт has pleased your President to style as an "address" what I wish to present to you in an informal way, in reference to an investigation into the economic wast of unnecessarily discharging employees. I have no heretofore spoken publicly on the subject, and have unsuccessfully tried to dodge it at this time, mainly for the reason that, in order to give proper background to the statements which I desire to make, I ought to present corroborating figures and facts, but cannot do so without divulging information given to me confidentially by a number of manufacturing concerns throughou the country. I shall be obliged, therefore, to use a illustrative figures aggregate statistics of several concerns rather than concrete examples of individual employments.

Everyone who is an executive knows how disheartening it is in industrial life to be obliged occasionally to dismiss employees in obedience to business condition and not at all on account of any fault of such employees. Disregarding the personal and human aspect of the problem, and looking at it solely from the cold business standpoint, it is at once clear that every unnecessary dismissal of an employee means a definite economic loss to the employer. If through the adoption of different methods than are now in vogue, this economi waste can be prevented either in whole or in part, it becomes a duty of the employer to himself and to hi employees to re-arrange his methods of employment in accordance with improved standards. Many employers have recognized the truth of this statement, and have found it profitable to maintain specialized employment departments in charge of competent managers They know from experience that it does not pay to hire and discharge haphazardly; they realize that it cost money to train an employee, even a skilled workman, in the special practices that are peculiar to a given concern, and that the dismissal of an employee, except for good reasons, means that the expenditure for his training has gone for naught and that an additional expens must be incurred in the training of a new employee.

Appreciating the situation, I have given some tim and thought to this subject and will present to-day an outline of my findings. I hope, at the same time, to make employers recognize more fully than they have in the past the importance of this phase of economic management.

A great deal has been said in the last few years, and properly so, about reducing the cost of production through so-called "scientific management," which endeavors to eliminate every "unnecessary motion" and every unnecessary expenditure. Hand in hand with, if not even preceding this effort, should go a well-directed endeavor for a closer analysis of the men whom we take into our employ, of the systems under which we train them in our work, and of the reasons for and th methods under which we let them go, only to have thei places filled again by new recruits.

My observations were concerned with large, medium size and small manufacturing eoncerns throughout th United States, all of which form a part of the mechanical industries. During the summer of 1913, while in Europe, I made similar investigations in factories in Austria, Germany, France and England. Information and statistics from these European factories would indicate that the problem under discussion is not only a national but an international one; it is so much the more surprising therefore, to find that it has received so little serious attention by sagacious business men on so little serious attention by sagacious
this and the other side of the ocean.

this and the other side of the ocean.

The investigation endeavored first to trace the curve of engagements and discharges in the various concerns during the period of one year, and then to secure and study the reasons for the discharges in order to find, if possible, practical remedies for the resulting situation. All data were obtained for the year 1912, which may be considered to have been an industrially normal year.

The investigation covered the employment and discharge of all classes of employees at the various factories except those belonging to the commercial and engineering organization and to the general executive staff. A record of those who had entered the service of the concerns for the first time and of those who had been working in the same place at a previous period was also obtained, for it was assumed that re-employment would usually cause a smaller expense than the employment of entirely new people unfamiliar with the conditions prevailing at a given factory.

*Delivered before the National Machime 'Tool Builders' Association, New York City.
For the group of factories for which I shall present figures in the aggregate it was found that of all people engaged during the year 1912, about 73 per cent were entirely new employees, and correspondingly about 27 per cent were re-engaged employees. As a general proposition, this percentage will apply fairly well to any normal employement in the mechanical industries. The group of factories just alluded to, covering the The group of factories just alluded to, covering the
employment of male and female persons and a great variety of mechanical manufacture requiring labor ranging all the way from the highest skilled to entirely unskilled workmen, gave employment to 38,668 employees at the beginning and 46,796 employees at the end of the year 1912. The increase in the working force, as between January 1st and December 31st, amounted, therefore, to 8,128 people. Yet the records show that during the same period 44,365 people were engaged, indicating that 36,287 people had dropped out of the employment during the year for whatsoever reason. In other words, about $51 / 2$ times as many people had to be engaged during the year as constituted the permanent increase of the force at the end of that period.

Several reasons might be given in explanation of this condition. It might be stated that the labor market in a given locality was in part responsible for the situation; it might be claimed that in a particular plant a temporary piece of work had to be done, such as the digging of a foundation or the building of a structure, for which labor in excess of the normal quota was needed temporarily, to be dispensed with again when needed temporarily, to be dispensed with again when
the special work was finished. Unusual conditions of employment may be pointed out as the result of a highly fluctuating productive situation, brought about in turn by a largely varying commercial demand on the factory during the four seasons of the year. Finally, sight must not be lost of the fact that some people die, others drop out on account of prolonged sickness, and still others leave the employment for reasons that could not have been obviated by the management.

The important fact, however, stands out that 44,365 people had to be engaged during the year to retain less than 20 per cent of that number.

Theoretically only as many people ought to have been hired as were needed permanently to increase the force. As business men we know, however, that theoretical conditions do not surround our commercial enterprises and that we must make certain allowances in order io view the problem in

(a) Men die and must be replaced;

(b) Men leave on account of sickness for sufficiently ong periods that their places must be filled by others;

(c) Men, even though they have been selected for their positions with good judgment, leave of their own accord because they do not find it possible to remain in their new positions, whether on account of climatic conditions, domestic affairs or oth

heir removal from the locality:

(d) Finally, it must be recognized that no employment department can run on a 100 per cent efficiency asis.

Taking these items into account, it must be clear that more than $\mathrm{X}$ people will have to be hired during a year in order to increase the working force by $\mathrm{X}$ persons. In an attempt to assign values to the four causes just enumerated, I have assumed that annually

1 per cent of all employees die;

5 per cent leave on account of prolonged sickness; 10 per cent withdraw for reasons that could not hav
been foreseen at the time of their engagement; and

75 per cent constitute a readily atcainable efficienc f an employment department.

These figures find their support in the following considerations:

After ascertaining the average age of employees in the group of factories under investigation, namely $311 / 2$ years for male and 23 years for female employees, I turned to insurance statistics and found that 8.5 out of every 1,000 male persons of $31 \frac{1}{2}$ years of age and 7.95 out of every 1,000 female persons of an average age of 23 , engaged in general factory employment, die annually. The experience of several mutual benefit association in factories, some extending over a period of almost 10 years, revealed that annually almost 7 in every 1,000 members were removed by death. These statisties, then, fully corroborated my assumption that death re moves 1 per cent of factory employees amnually.

Insurance statistics also slow that about is per cent of average factory employees are sick annually for periods of two weeks or more; this percentage drops considerably when sickness of three weeks' duration or more is taken into account. Again, the experience of mutual benefit associations fairly well agrees with the data of insurance companies. Knowing, however, the prevailing custom in most factories to carry on sick leave for much longer periods than two weeks those of whose sickness the management has definite knowledge, I have assumed that 5 per cent of all employees will have to be replaced on account of prolonged sickness and consequent withdrawal from the service.

As to the number of people who withdraw during the year for whatsoever other reason, except that of sickness and death, no reliable experience seems available. In fact, the only information that I could find is that contained in the United States Civil Service report, according to which 8 per cent of all government employees are separated from the service annually for any reason, including that of sickness and discharge. Realizing, however, that governmental employment conditions are different from those in industrial establishments, I have doubled the government estimate by allowing 16 per cent for withdrawal by death, sickness and resignation. or 10 per cent for withdrawal by unavoidable resignations alone.

Finally, I believe that a 75 per cent efficiency of an mployment department, and even a greater efficiency, should readily be attainable in a highly specialized department in charge of one or a few persons.

It follows, therefore, that while theoretically 8,128 people should have been employed to allow for an increase of the working force by that number, 11,825 persons should have been engaged in addition, to cover withdrawals by death, sickness and resignation, and to allow for practical employment results. If we take cognizance, furthermore, of normally fluctuating productive conditions necessitating at times more and at times less employees, and of unpreventable exigencies of the labor situation, we could make a further allowance of 2,187 persons, representing 5 per cent of the total working force throughout the year.

While theoretically, therefore, only 8,128 persons should have been engaged, practically the engagement of 220140 could readily be defended.

What should be said, however, of the fact that in order to increase the force during the year by 8,128, 44,365 total had to be engaged, of whom 22,225 were therefore engaged above the apparently necessary requirements?

It is obvious that a considerable sum of money must have been wasted in engaging and correspondingly discharging unnecessarily so large a force of men and women. In order to secure a lucid picture of this fact, I have tried to assign a dollar-and-cents value to the figures ust quoted. No reliable investigation seems to have been made and published in respect to such financial valuation. Industrial managers were, therefore, interviewed in an effort to obtain from them if possible a consensus of opinion. They were rather loath to express their views because they had not given heretofore serious thought to the question. Their estimates ranged from $\$ 30.00$ to $\$ 150.00$ per employee; few placed the financial valuation of the waste at less than $\$ 50.00$ per employee and some went even as high as $\$ 200.00$ per employee. The great difference in these estimates is no doubt due to the diversity of the industries which these managers represented.

One machine tool builder, who is usually very keen in following up matters of this kind, after they have been called to his attention, looked into the subject with some care and stated it as his belief that the engagement of almost 1,000 persons in his plant during one year, while the permanent increase in his force amounted to less than 50 , reduced his profits by fully $\$ 150,000.00$; he therefore estimated the economic waste of the unnecessary engagement of an employee at about $\$ 150.00$. The head of a large automobile manufacturing concern stated with equal positiveness that the engagement of a new employee would involve an expenditure of at least $\$ 100.00$. This statement is so much the more surprising as it is well known that on account of the high wages paid in the automobile industry generally, and in the plant referred to in particular, the management should be able to cornmand the best type of labor both as to technical skill and general discipline; and this should materially reduce the cost of training new employees. Still another manager who employs a great deal of female, as $\$ 200.00)$ per employee.

Unquestionably the skill, experience and intelligence 
of a new employee has much bearing upon the amount of money that needs to be expended for his training. Another important consideration is whether the new employee is working on expensive or low priced machinery, or with high or low priced tools, or on expensive or cheap material; and to a certain extent whether o not he has been employed before in the same shop and particularly on the same class of work.

This thought led me to subdivide the employees under investigation into several groups and to study each group as to its requirements for the training of an employee both as to quantity and quality of the instruction. Accordingly, I established the following classes:

Class A, comprising highly skilled mechanies who must have practiced their trade for a number of years in order to attain the required high degree of all-round experience and proficiency;

Class B, comprising mechanics of lesser skill and experience, who likely could acquire an average degree of proficiency within a year or two;

Class C, composed of the large number of operatives, usually known as piece workers, who without any previous skill or experience in the particular work attain efficiency within a few months, depending on the chararter of the work.

Class D, including all unskilled productive as well as expenselaborers who can readily be replaced in the course of a few days; and

Class E, comprising the clerical force in shop and office.

The employees assigned to each elass were again subdivided in the ratio of 73 per cent to 27 per cent, to separate those that may be assumed to be entirely new recruits from those who may be considered to have had
previous experience in the same factory.

On this basis, the following distribution of the employees was obtained:

\begin{tabular}{|c|c|c|c|c|c|c|}
\hline \multirow{2}{*}{$\begin{array}{c}\text { In } \\
\text { Class }\end{array}$} & \multicolumn{3}{|c|}{ Total Engagements } & \multicolumn{3}{|c|}{ Unnecessary Engagements } \\
\hline & All & New & Old & All & New & Old \\
\hline $\mathbf{A}$ & 4,881 & 3,563 & 1,318 & 2,445 & 1,785 & 660 \\
\hline B & 6,519 & 4,759 & 1,760 & 3,266 & 2,384 & 882 \\
\hline $\mathrm{C}$ & 15,087 & 11,014 & $4,0 ? 3$ & 7,558 & 5,517 & 2,041 \\
\hline $\mathrm{D}$ & 14,905 & 10,881 & 4,024 & 7,467 & 5,451 & 2,016 \\
\hline $\mathbf{E}$ & 2,973 & 2,170 & 803 & 1,489 & 1,087 & 402 \\
\hline All & 44,365 & 32,387 & 11,978 & 22,225 & 16,224 & 6,001 \\
\hline
\end{tabular}

The next question is: What factors mainly contribute to the cost of training a new employee?

This cost may be considered to result from:

(a) Clerical work of hiring;

(b) Instruction of new employees by foremen and assistants

(c) Increased wear and tear and damage of machinery and tools;

(d) Reduced rate of production during early period of employment; and

(e) Increased amount of spoiled work by new employees.

The expense of the clerical labor of hiring will be small per individual, somewhere in the neighborhood of 50 cents for each employee.

The instruction expense, on the other hand, will vary largely in amount according to the skill and experience of the new employee and the nature of his work. It will be lowest for Class D and highest for Class C employees, for the latter must be instructed most and watched longest. Without now taking the time for a detailed explanation of the conclusions, I feel justified in assigning the following expense values, to wit:

Per Employee
Class A $\ldots \ldots \ldots \ldots \$ \mathbf{7 . 5 0} \quad$ Class D $\ldots \ldots \ldots \ldots \$ 2.00$
Class B $\ldots \ldots \ldots \ldots 15.00$
Class C $\ldots \ldots \ldots \ldots 20.00$

The value of the increased wear and tear and the damage of machinery and tools by new employees is difficult to estimate. It will be little if anything for $\mathrm{Cl}$ iss $\mathrm{D}$ and $\mathrm{E}$ employees, for whom it may be presumed to be $\$ 1.00$ per employee. It may reach thousands of dollars for damage to expensive machinery in the keeping of Class A, B, and C employees for whom an amount of $\$ 10.00$ each would be very reasonable.

The loss due to reduced production is entirely dependent upon the value of the produced article and the experience and skill required for its production. On the basis of some investigation as to how soon employees in the various classes are able to reach normal productive efficiency in a factory new to them, and with due regard to preva

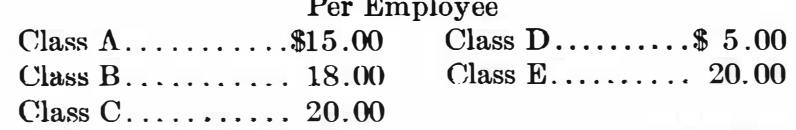
Similarly, for the expense of spuiled work, which varies with the value of the raw material and/the labor expended on it, I have assigned $\$ 15.00$ for each Class
A, B and C employee, and practically nothing for Class $\mathrm{D}$ and $\mathrm{E}$ employees.

The respective totals of these items show that the cost of training new employees amounts to the following:

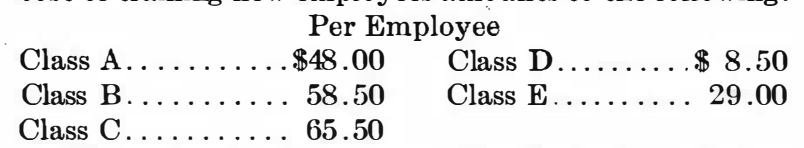

Bearing in mind the assumption that about 27 per cent of newly engaged employees had worked before in the same factory, the cost of their new training should be considerably reduced, even though this reduction would seem justified only if the employee were put back on exactly the same class of work upon which he wa previously engaged. A conservative estimate would place the expense of breaking in re-hired employees at $\$ 10.00$ in Class A, $\$ 20.00$ in Class B, $\$ 35.00$ in Class C, $\$ 500$ in Class D and $\$ 10.00$ in Class $\mathrm{E}$ for each such employee.

Out of these considerations grows the astonishing conclusion that the apparently unnecessary engagement of 22,225 employees within one year, in the group of factories under investigation, involved an economic loss of $\$ 7 \gamma 4$, 139.00

This means that the cost of training a new employee taking all in all, amounted to $\$ 34.85$ or about $\$ 35.00$, which noi only comes within the range of estimate heretofore mentioned, but brings the figure practically ear the lower limit of the estimates.

This important question immediately arises: How can dollars be aysary loss of about three-quarters of a millio Five answers present themselves readily:

1. An adequate study of current employment statistics and a careful analysis of the reasons for the discharge of employees will furnish a fact basis of great value;

2. High-grade men must be placed in charge of the hiring departments of concerns;

3. The exercise of proper methods for the taking care of new employees is an exceedingly important problem;

4. Effective systems of apprenticeship and specialized training courses must be maintained; and

5. Commercial requirements should be so regulated as to secure a fairly uniform productive situation throughout the year.

It should be unnecessary to point out that the reason for the voluntary or involuntary leaving of an employe as given by the foremen on the discharge cards cannot be fully relied upon, and that special effort should be made to get at the real reason for an employee's discharge so as to secure a correct basis on which to build remedial action

In the light of the above statements and figures it should also be unnecessary to defend the necessity for the highest grade of judgment in the hiring and discharging of employees. The employment "clerk" o to-day will have to be replaced by the employmen "superintendent" or "manager" of to-morrow, no merely by changing the title of the man but by changing the type and character of the man even though this will mean a higher salary. Second in importance to the manager of the plant should be the assistant who is entrusted with the duty of bringing into the plant th men and women that are needed from time to time, and of keeping them there, contented and efficient. What methods to employ to take care of employees from the very moment when they start in their new work is a far more important question and presents a far more difficult problem than that of the proper selection of new employees from among the applicants for the job. The very best thought on the psychological side of industrial management will have to be applied to this particular phase.

It has been recognized for some years, even thoughnot perhaps as fully as should be, that it is the duty of industrial managers so to take hold of the youth of the land and properly train the boys and girls who wish to or by circumstances may be obliged to choose a vocational occupation for their livelihood, that they may become intelligent, skillful and contented workers and leaders in our constantly growing industrial army. Although to a certain extent all managers take an interest in this problem of providing an adequate supply of properly trained workers, many have not yet discovered that it will be essentially worth while to set aside the required time from their busy life and to devot appropriate effort and financial support to this issue.

As for the last suggested remedy to bring about a more evenly arranged production throughout the year, I can only express the belief that much good to all concerned can be accomplished in this respect, and $\mathrm{I}$ am encouraged in this feeling by the growing examples of standardization of product which brings with them ability to manufacture for stock as well as for immediate delivery, thereby permitting the maintenance of a fairly ven production throughout the year.

Along the five lines of remedy herein suggested lies, to my mind, the solution of a problem which looms large before our eyes and will loom larger as competition will row keener. The "Man" problem as contrasted with the "Material and Machine" problems will and must in future engage more fully and more keenly our best attention.

It is somewhat reassuring at the present time, although may not remain so for long, to know that the conditions of employment berewith presented do not seem to be any better in European industrial countries. Merely in support of this statement, the following illustrations, drawn from factory experience in Germany and England, may be of interest:

\begin{tabular}{c|c|c|c|c}
\hline & $\begin{array}{c}\text { Employees at } \\
\text { Feginning of } \\
\text { Year }\end{array}$ & $\begin{array}{c}\text { Emplovees at } \\
\text { End of Year }\end{array}$ & $\begin{array}{c}\text { Totallncrease } \\
\text { During the } \\
\text { Year }\end{array}$ & $\begin{array}{c}\text { No. Persons } \\
\text { Hired }\end{array}$ \\
\hline 1 & 13,556 & 16,450 & 2,894 & 9,530 \\
2 & 10,998 & 11,914 & 916 & 17,059 \\
3 & 9,165 & 12,032 & 2,867 & 10,982 \\
4 & 3,158 & 3,149 & Minus 9 & 2,148 \\
5 & 365 & 470 & 105 & 637 \\
& & & &
\end{tabular}

In presenting to you the results of my investigation nto the waste of hiring and discharging employees, I have made no effort to paint a black picture but have merely presented the varied colors of the industrial spectrum. I have pictured what seems to be an average condition throughout the country. Time has not permitted to place before you a detailed analysis of the contributing causes and remedial actions for the problem under discussion; however, "a word to the wise is sufficient."

I now elose with an earnest plea that you give the problem careful consideration and indulge in similar investigations in your own factories to assure yourself of the state of your affairs and, where necessary, to correct unsatisfactory conditions. It will also give you a more concrete knowledge of the subject, so that a future discussion of it may be conducted with a more assured hopefulness of finding and applying the right remedy or remedies for an unsatisfactory situation. Through a correct solution of the problem we shall not only contribute materially to the welfare and prosperity of the industries, but also to the contentment and wellbeing of the thausands and thousands of employees who cannot be benefited in any degree by short-time and haphazard employment.

In view of certain legislative and administrative tendencies now affecting American industries, it is important also to reflect that constant fluctuation in the working force of an establishment must materially increase the difficulty of maintaining among the employees loyalty to the management, esprit de corps and general contentment. Just as little as we shall be able to take quicksand and knead it in our hands into a solid lump, so also will we find it impossible to take hold of an everchanging mass of employees and transform it into a homogeneous, intelligent, contented body; furthermore, this condition will nullify to a large degree the beneficial effect of many well-intentioned efforts of the management, such as sickness and accident insurance plans, pension systems and other phases of industrial betterment work.

And last but not least, the problem of employment offers an opportunity for constructive work in which employers and employees can readily be brought together for mutual benefit, for no right-thinking man, whatever his position, can justly object to any well-directed plan which will give employees continuous work throughout the year and will enable employers to maintain steady production.

\section{Froperties of Selenium}

AN extremely interesting report of an investigation of the crystal forms of metallic selenium by Mr. F. C. Brown recently appeared in the Physical Review. In this research a large number of new crystals of metallic selenium were formed, some of very large size. All of these forms, except one, are very transparent selectively to light, a large amount of light penetrating to a greater depth than 0.2 millimeter. All the crystal forms in crease in conductivity when illuminated, and with but one exception they have been observed to be doubly refracting. The action of light is in the selenium itself and not at the contacts. Mechanical pressure produces a genuine change in the selenium, which may alter the conductivity more than a thousand times. The absolute change of conductivity in one crystal by constant illumination was proportional to the conductivity in the dark, when that conductivity was altered by pressures between 1 atmosphere and 180 atmospheres. The temperature at which the crystals sublimate in mass influences the character of the wave-length sensibility curves. The production of individual crystals of metallic selenium of large size opens up a wide field of investigation which promises to be free from sume of the possible complexities in seleniun cells. 